\title{
Transition to adult services for children and young people with palliative care needs: a systematic review
}

\author{
M Doug, ${ }_{1}^{1}$ Y Adi, ${ }^{1}$ J Williams, ${ }^{2}$ M Paul, ${ }^{1}$ D Kelly, ${ }^{3}$ R Petchey, ${ }^{4}$ Y H Carter ${ }^{1}$
}

- Additional appendices are available online only. To view these files please visit the journal online (http://adc.bmj.com).

${ }^{1}$ Health Sciences Research Institute, Warwick Medical School,

University of Warwick, Coventry, UK

${ }^{2}$ School of Pharmacy, University of Nottingham, Nottingham, UK

${ }^{3}$ School of Health and Social Science, Middlesex University, London, UK ${ }^{4}$ City University, Northampton Square, London, UK

\section{Correspondence to \\ Manjo Doug, Health Sciences Research Institute, Warwick Medical School, University of Warwick, Coventry CV4 7AL, UK; m.doug@warwick.ac.uk}

Accepted 8 November 2009

Published Online First 30 November 2009

\begin{abstract}
Objective To evaluate the evidence on the transition process from child to adult services for young people with palliative care needs.

Design Systematic review.

Setting Child and adult services and interface between healthcare providers.

Patients Young people aged 13-24 years with palliative care conditions in the process of transition.

Main outcome measures Young people and their families' experiences of transition, the process of transition between services and its impact on continuity of care and models of good practice.

Results 92 studies included. Papers on transition services were of variable quality when applied to palliative care contexts. Most focussed on common life-threatening and life-limiting conditions. No standardised transition program identified and most guidelines used to develop transition services were not evidence-based. Most studies on transition programs were predominantly condition-specific (eg, cystic fibrosis (CF), cancer) services. CF services offered high-quality transition with the most robust empirical evaluation. There were differing condition-dependent viewpoints on when transition should occur but agreement on major principles guiding transition planning and probable barriers. There was evidence of poor continuity between child and adult providers with most originating from within child settings.

Conclusions Palliative care was not, in itself, a useful concept for locating transition-related evidence. It is not possible to evaluate the merits of the various transition models for palliative care contexts, or their effects on continuity of care, as there are no long-term outcome data to measure their effectiveness. Use of validated outcome measures would facilitate research and service development.
\end{abstract}

A growing number of children and young people with what were previously fatal conditions of childhood, such as cancer, ${ }^{1}$ life-limiting conditions and other life-threatening conditions (LTC), ${ }^{2}$ are now surviving into adulthood, due to advances in treatment. Transition to adult services for young people with palliative care needs is, therefore, a contemporary concern. Such transitions can be complicated by deteriorating physical health and/ or cognitive abilities, alongside normal developmental changes.

Policy initiatives and developments around transition and palliative care have become increasingly common. ${ }^{3-5}$ The Department of Health recently launched their first Children's Palliative Care Strategy "Better Care: Better Lives". 6 The strategy reinforces many of the views expressed

\section{What is already known on this topic}

- The increased life expectancy of young people with life-threatening and life-limiting conditions has raised the importance of transition to adult services for young people with such conditions.

- There is increasing literature and attention around transition services for young people, but this has mainly focused on areas such as chronic illnesses and disabilities.

\section{What this study adds}

- There is no evidence of transition services that address "palliative care" as an overall concept. Transition programs that exist are mainly condition-specific.

- No long-term outcome data exist to compare the effectiveness/cost effectiveness of the condition-specific or generic transition models.

- Some consensus exists on what may facilitate or impede successful transition programs. This suggests transition programs should be multidisciplinary in nature, individualised in terms of addressing need and navigated with the help of a designated key worker.

in the Independent Review of Children's Palliative Care, which acknowledges that there is: "currently poor co-ordination of public services across the statutory and voluntary sectors, particularly transition between children's and adult services." Identification of the unmet needs of this population resulted in the recent publication of a framework for Integrated Multi-Agency Care Pathways by the Association of Children's Palliative Care (ACT). ${ }^{8}$

The concepts of palliative care and transition which are central to this review are complex. Although there is considerable agreement between different definitions of palliative care, the absence of a universal definition means that at the condition level, any definition is, to some degree, arbitrary and, hence, open to challenge. ${ }^{9-12}$ In determining which conditions to include and exclude in this systematic review, we were guided by the contemporary Association of Children's Palliative Care/Royal College of Paediatrics 
and Child Health (ACT/RCPCH 1997/2003) definition of life-limiting conditions (LLC). ${ }^{9}$

Transition has been commonly described as "The purposeful, planned process that addresses the medical, psychosocial and educational/vocational needs of young people and young adults with chronic physical and medical conditions as they move from child-centred to adult-oriented healthcare systems." ${ }^{13}$ Healthcare providers require evidence on which to develop services that are appropriate and effective for young people so that their care should not be compromised or "lost in transition" by the transfer to an adult system. ${ }^{14}$ The scope of this systematic review was to evaluate the evidence on transition from child to adult services for young people with palliative care needs, exploring the impact of the transition process on continuity of care, young people and their families' experiences and to identify models of good practice.

\section{METHODS}

\section{Search strategy}

We used medical subject headings and key words to search systematically five databases (Medline, CINAHL, PsychINFO, British Education Index and the International Bibliography of the Social Sciences) from January 1995 to February 2008. An initial search strategy was devised and subsequently revised through an iterative process involving all members of the team (see online appendix 1). Key words included "transition", "child", "young people", "adolescent", "palliative care", "terminal care", "nursing practice", "LLC" (such as "CF") and "LTC" such as "CHD" and "cancer". We also searched the reference lists of included studies and sought additional literature through contact with experts in palliative care.

\section{Study selection}

We included studies if participants were as follows: (1) young people aged 13-24 years with palliative care conditions, defined using our criteria (table 1); (2) relevant to situational transition, that is, transition from child services to adult services and/or between healthcare providers and (3) original articles, reviews, systematic reviews, consensus policies, guidelines and survey recommendations. Excluded from the systematic review were studies whose: (a) participants had chronic disorders which were not intrinsically life-limiting (eg, diabetes, rheumatological and endocrine disorders); (b) developmental disorders (eg, severe and profound learning disabilities); (c) transplant recipients; (d) social status transition (ie, from childhood to

Table 1 Four areas of life-limiting conditions ${ }^{9}$

\begin{tabular}{ll}
\hline Areas & Examples of conditions \\
\hline $\begin{array}{l}\text { 1. Life-threatening conditions for which } \\
\text { curative treatment may be feasible but } \\
\text { can fail }\end{array}$ & $\begin{array}{l}\text { Cancer } \\
\text { Cardiac anomalies } \\
\text { Irreversible organ failure }\end{array}$ \\
$\begin{array}{l}\text { 2. Conditions that may entail long periods of } \\
\text { intensive treatment aimed at prolonging } \\
\text { life and allowing participation in normal } \\
\text { activities, although premature death is still } \\
\text { possible or inevitable }\end{array}$ & $\begin{array}{l}\text { Cystic fibrosis } \\
\text { Duchenne muscular dystrophy } \\
\text { HIV/AIDS }\end{array}$ \\
$\begin{array}{l}\text { 3. Progressive conditions without curative treat- } \\
\text { ments, where intervention is exclusively pallia- } \\
\text { tive, although it may continue for many years }\end{array}$ & $\begin{array}{l}\text { Batten disease } \\
\text { Mucopolysaccharidosis }\end{array}$ \\
$\begin{array}{l}\text { 4. Coutzfelt Jacob disease } \\
\text { neurologitions associated with severe }\end{array}$ & $\begin{array}{l}\text { Brain or spinal cord } \\
\text { injuries }\end{array}$ \\
$\begin{array}{l}\text { progressive but can entail weakness and } \\
\text { susceptibility to health complications }\end{array}$ & \\
leading to premature death & \\
\hline
\end{tabular}

adulthood); (e) health status transition (ie, from relative health to illness or to end of life care) and (f) articles that did not provide English language abstracts.

A shortlist of papers was initially identified using titles and abstracts. The steering group reached consensus on titles and/ or abstracts for inclusion. Papers, whose abstracts provided insufficient information, were considered in full to decide on inclusion or exclusion.

\section{Main outcomes}

We focused on three outcomes: the experiences of transition and their impact on young people, their families, carers and service providers; the process of transition on continuity of care and models of good practice for the transition process.

\section{Quality assessment}

We used a validated scoring system for systematically appraising empirical studies with varied methodologies, including qualitative studies. ${ }^{15}$ Each study component (total eight) of the full text paper was given a quality score ranging from 1 (very poor) to 4 (good) which generates a maximum potential score of 32 (see online appendix 2). Discrepancies were resolved by consensus.

\section{Data extraction}

Two reviewers from a list of four (MD, YA, DK, RP) independently completed a standardised data extraction form for each included full text paper. Any differences were resolved by consensus.

Extracted information included items referring to citation details, reviewer initials, study design, setting and participants (palliative care condition, age), as well as interventions, outcome measures and a total quality score (if applicable).

\section{Data analysis}

SPSSV.15 was used to manage the data extraction process and perform frequency analyses of the search findings. Metaanalysis of the findings was not feasible due to the heterogeneity of papers and limited measures of effectiveness/ outcomes. The findings are, therefore, integrated in a narrative synthesis.

\section{RESULTS}

Figure 1 describes the paper selection process. The searches identified 3493 citations of which 252 were potentially relevant and their abstracts reviewed. After second screening, 128 full-text articles were examined in detail. Ninety-two papers met the inclusion criteria and were from a variety of countries around the world: USA $(\mathrm{n}=42)^{1316-55}$; UK $(\mathrm{n}=27)^{56-82}$; Australia $(\mathrm{n}=11)^{83-93}$; Canada $(\mathrm{n}=8)^{94-101}$; Denmark $(\mathrm{n}=1)^{102}$; Switzerland $(n=1)^{103}$; Germany $(n=1)^{104}$ and South Africa $(n=1) .{ }^{105}$

There were no studies reporting findings from randomised controlled trials, comparative trials or any economic evaluation of a transition program and only one systematic review on transition, but this was for a mixture of conditions to include a chronic condition (diabetes) and learning disability. ${ }^{82}$ The most predominant transition model was the condition-specific model. 254793 Only one example of consumer involvement in any of the established programs was found ${ }^{92}$ Three further models were described by Miller $(1996)^{72}$ : the paediatric service to adult service direct; the paediatric service to transition clinic to adult service; and the paediatric service to adolescent clinic to young adults clinic to adult service. 


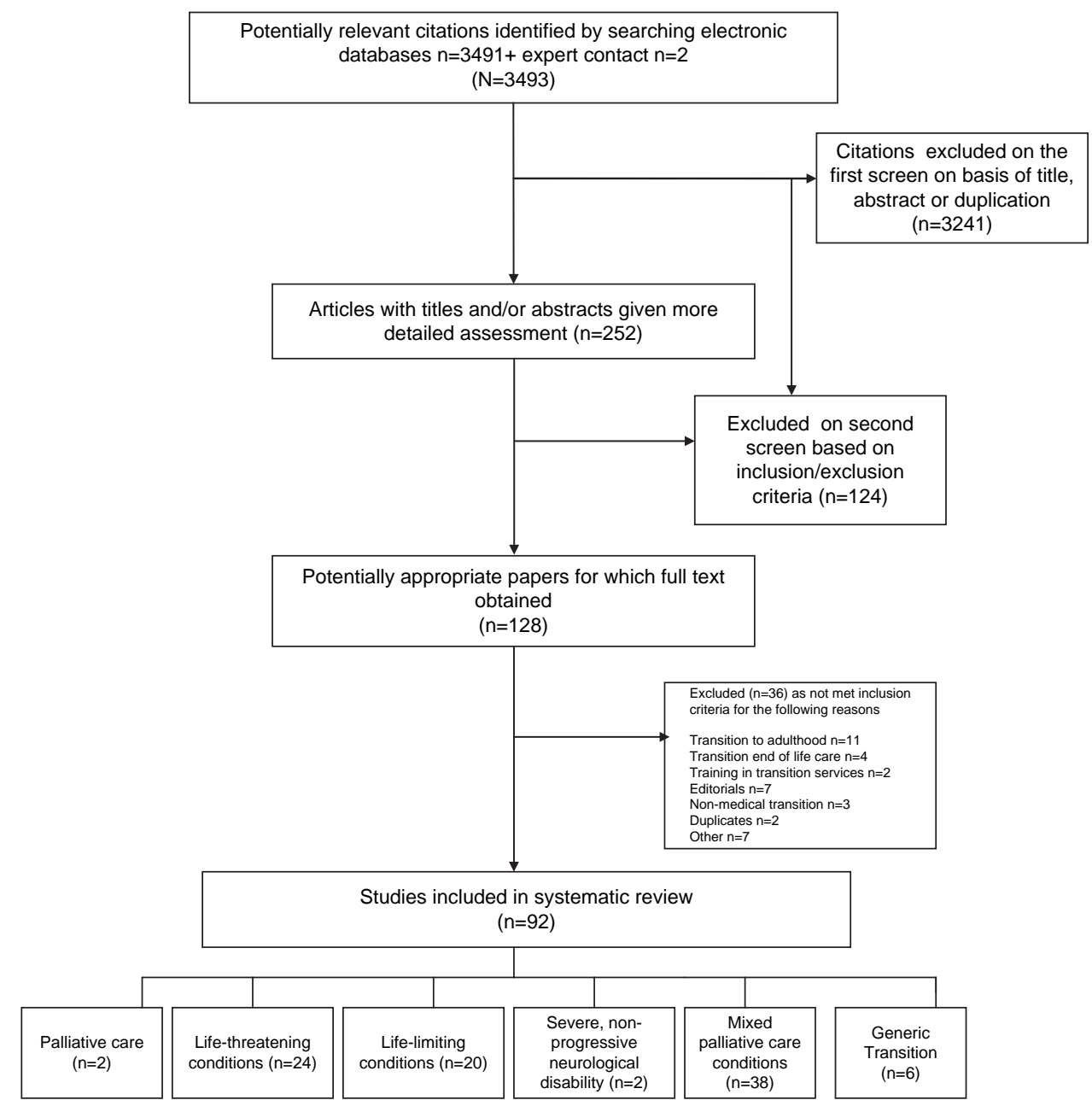

Figure 1 Flowchart for systematic review.

\section{Methodological quality (empirical studies)}

Only 31 out of the 92 articles (34\%) were classified as empirical studies and could be fully quality-assessed/scored according to the eight study components. ${ }^{15}$ These empirical studies varied in design with only a few high scoring ones ranging from 18-31 out of 32 (see online web appendix 3 ). The mean score for studies was $24, \mathrm{SD}=3.4$. The remaining articles (non-empirical) were reviews, descriptions of services, policy or position papers.

\section{Description of included studies (empirical and non-empirical) Palliative care}

Only three papers used the term "palliative care" as an overall concept in relation to healthcare transition from child to adult services and were all non-empirical. ${ }^{56} 6068$ Edwards $(2001)^{60}$ described a model of palliative care for a young person with cancer (and this is included in the count of papers for cancer).

\section{Conditions and transitions}

Most of the identified papers focussed on specific conditions that fall under the umbrella term of palliative care. We allocated these to the "condition groups" detailed below (corresponding to table 1).

\section{Life-threatening conditions}

There were a total of 24 papers on LTC. ${ }^{1} 1618-2024252729303336$ 4550556062757881959798102

Four predominant CHD transition models have been proposed: the paediatric model (care received from paediatric providers, facilities and programs); the adult model (care received from adult providers); the blended model (care received from paediatric and adult providers, facilities and programs) and the "drop out" model (no care received). ${ }^{19}$ As there remains controversy over the best model for CHD, the "blended model" of care was often used due to the fact that most young people remained with their paediatric cardiologist because adult congenital heart centres and adult cardiologists experienced in CHD were lacking. ${ }^{27}$ It was often difficult for child healthcare providers, patients or parents to terminate their long-term relationships, and as a result, a transition to an adult program often does not occur, and this was termed the "drop-out" model.

CHD papers indicated that there remains controversy on the age at which transition should occur. Proposed strategies for facilitating the CHD transition process include the patient passport ${ }^{45}$ and the patient transition tool. ${ }^{97}$

Four transition models were proposed for young people with cancer: a condition/disease-specific model (management of a specific condition by paediatric providers, working directly with adult providers, to ensure prioritisation of the management of the physical condition); a generic adolescent model (a young person's/adolescent health specialist coordinates developmentally appropriate, holistic care, covering the young person's biological and psychological concerns); a primary care model (coordinated by the general practitioner, which has met considerable opposition because of a lack of integration between primary 
and specialist care) and a single site model (the same clinical environment is used, ie, the young person moves from child to adult care within the same healthcare system). ${ }^{25} 29$

None of the above cancer transition models alone seem adequate, and a multidisciplinary, coordinated model, providing continuity of care throughout the disease course from child to adult services, is proposed as optimal. ${ }^{24}$ A good example is provided from the Living Well after Cancer program in the USA. ${ }^{25}$

\section{Life-limiting conditions}

There were 20 papers on conditions requiring intensive treatment to prolong life and maximise functioning. ${ }^{21} 222840$ 5354 57-59 65-67 71 858688100104105 All HIV studies53 6471 were empirical, ${ }^{64}$ promoting the development of individualised transition plans for each family, the provision of appropriate environments and continuity of care from a known provider. No studies were found of Duchenne Muscular Dystrophy as a single condition although it was included in three papers categorised under mixed palliative care conditions. ${ }^{637082}$

CF was the predominant condition in this category with the most empirical studies (eight), 212254678586104105 with some evaluation of transition programs. 6586104 CF was an example of a condition which had high quality transition services. However, there was also wide variation in policies and practices regarding the transition process for young people. Transition programs were often based within established CF centres but were not standardised. Overall, transition was challenging when adult teams were separated from the paediatric teams with the majority of young people wanting to see the adult CF physician at the paediatric hospital (81\%). ${ }^{88}$ In addition, there were varying viewpoints on the ages when transition should occur. ${ }^{28} 5467105$ The experiences of young adults with CF showed that the successful elements of a transition program were orientation tours, information provision and the presence of a familiar face at the adult clinics. ${ }^{85}$

\section{Progressive conditions without curative treatments}

There were no published papers located that addressed this topic.

\section{Severe, non-progressive neurological disability}

Two empirical studies ${ }^{39} 101$ reported on numbers of young people with these conditions making the transition to adult care and their ages at transition. Mothers were key to managing the young person's personal health record on the transition from child to adult services. ${ }^{39}$

\section{Mixed palliative care conditions}

A number of other papers could not be easily categorised under single "condition groups" because they addressed mixtures of palliative care conditions (any combination of CF, CHD, muscular dystrophy, cancer, HIV, disability, spina bifida) under the label of (a) chronic illness $(n=13)^{1323} 31344647495173768790103$ with five of these being empirical studies. ${ }^{47} 49737687$ The general themes from this cohort of papers were strategies to facilitate transition; exploring barriers to the transition process and the requirement for individualised transition plans providing multidisciplinary and collaborative care. ${ }^{34} 4976$ Two main models were observed in a survey which identified and characterised transition programs for young people with chronic conditions: a "young person model" (38\%) and the majority a conditionspecific model (62\%). ${ }^{47}$

There were nine papers on (b) chronic illness and disability. $637080828491-9399$ In the only systematic review, four transition models promoting continuity of care were identified: the direct transition model, where continuity is achieved when the young person is transferred to adult care safely and efficiently with the focus on relations between services; the sequential transition model, which addresses the young person's changing needs, in which services are an extension of child provision or offered jointly between adult and child providers; the developmental transition model, with the main focus on personal growth and development, and the professional transition model, which is not focused on the young person but on the professional responding to the young person's needs, that is, it releases expertise from one service type to the other (either child or adult). This latter model was common in conditions with short life expectancies or where expertise is located heavily within one service, for example, CF or HIV. They also found very limited evidence showing good practices which address continuity of care during the transition from child to adult services with regard to parents and carers. ${ }^{82}$

Three main transition models have been proposed for young people with chronic illness and disability, and these are similar to the cancer models described in the earlier section (but does not include the single-site model). ${ }^{93}$ There were three established transition programs for young people with a chronic condition or disability in Australia: Transition Care Program in Chronic Illness; Victorian Transition Project; Five-Year Transition Plan and consumer participation was integral to all three. ${ }^{92}$

Nine papers were identified on conditions classified as requiring special healthcare needs, ${ }^{17} 35373841-434894$ and four of these were empirical studies. ${ }^{35} 374148$ There were four predominating models of healthcare delivery described for young people with special healthcare needs, and these are the same as those for CHD (paediatric, adult, blended and drop-out). The key factor was parental involvement during the transition process. ${ }^{3548}$ High-quality parent-provider relationships were strongly associated with addressing transition issues. ${ }^{48}$

There were only two papers for (d) special healthcare needs and disability exploring young people's perspectives on strategies for successful transition. ${ }^{4452}$ White, $(2002)^{52}$ discusses the key elements of a successful transition program with a selected list of helpful resources for health professionals, families and young people.

There were three papers on (e) general disability 838996 and only one empirical study among these. ${ }^{89}$ The process of transition and achieving transition were described as problematic for this group, although an evidence-based transition framework had been used in Canada to help families and young people with disabilities make the transition. ${ }^{96}$

Two papers did not correspond with the definitions of palliative care outlined in table 1, and these were: epidermolysis bullosa ${ }^{61}$ and paediatric illness (empirical). ${ }^{26}$ Both highlighted the importance of having transition programs because of the increasing numbers of young people surviving into adulthood and the role of the family in improving the transition process.

\section{Generic transition}

There were six papers on generic transition, 326972747779 and two of these were empirical. 6972 The main themes resulting from this cohort were key elements considered important for effective transition programs and the identification of effective strategies as well as barriers (see below).

\section{Facilitators and barriers to transition programs}

Many of these papers described recurring themes. Three key principles that underpinned a successful transition process were information, communication and planning/coordination. Other 
elements considered helpful in successful transition programs are listed in table 2. They apply at the levels of healthcare organisations, healthcare professionals (whether in paediatric or adult healthcare settings), the young person themselves and his/her parents/carers/families. Underlying factors which may impede transition from child to adult services included service-based demands; restrictions in relation to service provision and personal preferences (table 3 ).

\section{DISCUSSION}

Our main finding was the lack of evidence of transition services that include "palliative care" as the originating concept. The evidence base is primarily derived from the area of LTC or LLC rather than palliative care itself. This may reflect shifting constructions of palliative care away from end of life to include long-term supportive care. Two main types of transition services existed for young people with such conditions: those underpinned by condition-specific models of transition (mainly for young people with CF, cancer or chronic conditions) and generic models of transition, such as holistic, developmentally appropriate, young person's/adolescent health-focussed services.

There was a lack of standardised transition programs and only a few models of good practice available in the literature. Good-quality empirical evaluations of condition-specific or generic models of transition were sparse and outcome data mainly existed in relation to CF and CHD. One of the challenges facing healthcare providers is how to move forward with service developments in terms of transition given the diversity of the conditions and relatively small numbers of young people involved. These are key research and service evaluation challenges that will have to be addressed if responsive transition services are to be developed.

Most of the recommended guidelines for transition programs lacked a robust evidence base. The majority of empirical studies had small sample sizes ${ }^{39} 416771727685$ and the transferability and generalisability of findings were also limited as findings may only be relevant to the population under assessment. It is clear that gaps in service provision need to be considered alongside the current state of the evidence concerning transition.

Fragmentation also existed between child and adult providers, with evidence of poor continuity of care, which made it difficult and problematic for many young people to negotiate the transition period. Significant differences between child and adult providers have been noted. ${ }^{39} 44$ The role of the family in facilitating transition seems key and has some evidence-base. ${ }^{31} 3675$ Individualised, flexible transition plans that take into account the views of young people and their families are advocated. There was also evidence emerging of specialist's young people's clinics for cancer ${ }^{81}$ and HIV $^{71}$ to facilitate the transition process.

Lack of access to, and availability of, appropriate comparable adult services for young people approaching transition was a key concern expressed by many young adults, families, carers and child health providers/organisations. Services need to be flexible and appropriate for chronological age and developmental stage. There seems little doubt that young people prefer same-age groupings and recognise the problem of moving away from the familiar paediatric environment to an adult service. Having an intermediate service could be hypothesised as positive; however, generic or specialist adolescent transition services require further evaluation.

Appropriate education and training is essential for those providing care for young people making transitions from child to adult services. Ideally, a key-worker should guide young
Table 2 Facilitators for a successful transition process between child and adult healthcare professionals, health systems, young people, families and carers

Transition/adolescent clinic where patient is seen by the paediatrician and the general physician together is effective for example, in cystic fibrosis ${ }^{73} 105$

Adult orientated primary healthcare from appropriately trained and certified professionals in adult healthcare settings ${ }^{45-47} 5387$

Healthcare passports ${ }^{18} 2745$

Child and adult providers collaborate and agree on a workable written transition plan $^{730}$ at joint clinics ${ }^{34}$

Communicate and share responsibility for transition between teams and with patients 3839609196

Develop a medical summary transfer form "transition note" 39 and/or information pack about adult services ${ }^{73}$

Adolescent autonomy checklists (assess patient readiness for transfer) ${ }^{18} 87$ Continue the successful aspects of the paediatric plan at transition ${ }^{32} 43$

To start transition years before the transfer date, ongoing communication and effective feedback from the adult care centre once transfer has occurred ${ }^{80}$

Individualise date of transfer for patients with special needs_-"social and medical stability" 87

Identify named professional (key worker) for contact point during transition for young people for example, transition nurses, ${ }^{41}$ transition workers/coordinators ${ }^{1373748085}$

Encourage patients as partners in their care ${ }^{80}$

Patients and families view as co-experts ${ }^{41}$

Internet information of resources, website links and internet chat groups ${ }^{18} 41$

Summer camps (CHD increasing-USA) ${ }^{50}$

Promote self-care/management throughout the transition period ${ }^{87}$

Young people and family involved in the transition process from beginning 2849617176

Patients and families have visited adult teams and in patient centres/support groups/orientation tours ${ }^{41} 7385$

Attend mentor programmes to pair young people with successful adults with a similar condition ${ }^{18} 41$

Table 3 Barriers for child and adult healthcare professionals and health systems, young people, families and carers that effect the transition process

Fragmentation of care between primary and specialty providers; paediatric and adult providers 24406389

Lack of available or appropriate/comparable adult services to provide consumer centred care that promotes autonomy ${ }^{49}$

Paediatric providers unwilling or uncomfortable terminating relationships "letting go" due to emotional attachments to the young person/family ${ }^{19} 43$

Paediatric providers lack of confidence with adult providers and the adult system ${ }^{88}$ Geographical issues related to location of available resources ${ }^{32} 4447$

Provider time constraints to address transition issues ${ }^{48} 91$

Poor communication between paediatric and adult providers 14058738991

Lack of condition-specific expertise in the adult system ${ }^{27}$

Adult providers lack of awareness about or comfort with adolescent age group and the transition process ${ }^{76}$

Lack of effective and evaluated models for transition 788493

Patients or family unwilling to make transition ${ }^{41} 49$

Medical insurance issues when reach adulthood (American) ${ }^{16} 2848$

Separation anxiety for patients and families leaving trusted and familiar healthcare providers 536971

Lack of preparation/planning for successful participation in the adult healthcare system 4144

Expectation of independence in negotiating and navigating the adult healthcare system $^{435}$

"Becoming burned out on healthcare". this has only been described in 1 paper $^{41}$

people through the process of transition, and the young person and family/carers should be viewed as co-experts. As Olsen $(2004)^{38}$ stated, "developing an individualised transition plan (a life (not illness) plan) facilitates transition and improves 
continuity of care". Peer-led models of support are also open to further exploration.

Professional issues include paediatricians' reticence to initiate the transition process because of anxieties and concerns that adult colleagues may not be familiar with the young person's palliative care needs. ${ }^{1} 2228294044668591$ The adult sector also has little experience of paediatric diseases that are now, with advances in medicine and technology, increasingly continuing into adult life. This represents a key challenge for the development of appropriate transition services for young people. The papers included in the review were, however, limited mainly to child health providers and settings. Research originating from adult services is, therefore, required. Findings from this systematic review should be used to identify the focus of further research that addresses which models of transition for young people, or components of differing models, can optimise outcomes. Use of evidenced-based facilitators, for example, and more nuanced knowledge of the barriers that impact negatively on the transition process would aid in developing interventions that can be tested in the context of complex transitional care.

The development of validated outcome measures are also necessary to determine the effectiveness of transition programs in the context of palliative care where healthcare needs may fluctuate more than in chronic conditions.

\section{CONCLUSION}

This review demonstrates a lack of available evidence comparing models of transition for young people with palliative care needs. Condition-specific transition programs do dominate but little evaluation has been carried out into their effectiveness. Further empirical research is warranted to compare models of transitional care, including long-term evaluation of existing programs, using validated measures to determine their effectiveness in relation to continuity of care, health and social care outcomes and cost effectiveness.

Acknowledgements Thanks to Professor Swaran Singh, Professor of Social and Community Psychiatry and Dr Daniel Munday, Associate Clinical Professor in Palliative Medicine both based at the Health Sciences Research Institute, University of Warwick as advisors to the study during the design and execution. Children's Hospices UK for funding this study. This paper was accepted for publication shortly after the untimely death of Yvonne Carter, after her long struggle with cancer. The authors are privileged to have worked with her and pay tribute to her enthusiasm, commitment and sense of fun. Her death diminishes us all.

Funding Children's Hospices UK.

Competing interests None.

Provenance and peer review Commissioned; externally peer reviewed.

\section{REFERENCES}

1. Freyer DR, Kibrick-Lazear R. In sickness and in health: transition of cancerrelated care for older adolescents and young adults. Cancer 2006;107:1702-9.

2. King N, Barclay B. Caring for young adults with neurological conditions. Eur J Palliat Care 2007:14:200-3.

3. Aiming high for disabled children: better support for families. London: HM Treasury/Department for Education and Skills, 2007.

4. The Royal College of Physicians in Edinburgh Transition Steering Group. Think Transition: Developing the Essential Link Between Paediatric and Adult Care, 2008

5. Transition, moving on well. A good practice guide for health professionals and their partners on transition planning for young people with complex health needs or a disability. London: Department for Children Schools and Families and the Department of Health, 2008.

6. Department of Health. Better care better lives. improving outcomes and experiences for children, young people and their families living with life-limiting and life-threatening conditions. London: DH Publications, 2008.

7. Craft A, Sue Killen S. Palliative care services for children and young people in England. an independent review for the secretary of state for health. London: Department of Health, 2007.
8. The Association for Children's Palliative Care. The Transition Care Pathway. A Framework for the Development of Integrated Multi-Agency Care Pathways for Young People with Life-threatening and Life-limiting Conditions. ACT, Bristol, 2007.

9. Guide to the Development of Children's Palliative Care Services. Report of the Joint Working Party. Association for Children's Palliative Care and the Royal College of Paediatrics and Child Health. ACT/RCPCH, Bristol, 1997.

10. NCPC. National Council for Palliative Care. 2008. http://www.ncpc.org.uk/ palliative care.html (Accessed 13 March 2008).

11. World Health Organisation. Definition of Palliative Care. WHO 2008. http:// www.who.int/cancer/palliative/definition/en/ (accessed Mar 2008).

12. National Institute for Clinical Excellence. Improving Supportive and Palliative Care for Adults with Cancer Manual. NICE 2004. http://www.nice.org.uk/ nicemedia/pdf/csgspmanual.pdf.

13. Rosen DS, Blum RW, Britto M, et al.; Society for Adolescent Medicine. Transition to adult health care for adolescents and young adults with chronic conditions: position paper of the Society for Adolescent Medicine. J Adolesc Health 2003:33:309-11.

14. McDonagh JE, Viner RM. Lost in transition? Between paediatric and adult services. BMJ 2006;332:435-6.

15. Hawker S, Payne S, Kerr C, et al. Appraising the evidence: reviewing disparate data systematically. Qual Health Res 2002;12:1284-99.

16. Balling KA. Surviving childhood cancer: the impact on transition to emerging adulthood. Dissertation Abstracts International: Section B: The Sciences and Engineering 2003;63:5154.

17. Bates K, Bartoshesky L, Friedland A. As the child with chronic disease grows up: transitioning adolescents with special health care needs to adult-centered health care. Del Med J 2003;75:217-20.

18. Betz CL. Adolescents in transition of adult care: why the concern? Nurs Clin North Am 2004;39:681-713.

19. Bjornsen KD. Health care transition in congenital heart disease: the providers' view point. Nurs Clin North Am 2004;39:715-26.

20. Fernandes SM, Landzberg MJ. Transitioning the young adult with congenital heart disease for life-long medical care. Pediatr Clin North Am 2004;51:1739-48, xi.

21. Flume PA, Anderson DL, Hardy KK, et al. Transition programs in cystic fibrosis centers: perceptions of pediatric and adult program directors. Pediatr Pulmonol 2001;31:443-50.

22. Flume PA, Taylor LA, Anderson DL, et al. Transition programs in cystic fibrosis centers: perceptions of team members. Pediatr Pulmonol 2004;37:4-7.

23. Freed GL, Hudson EJ. Transitioning children with chronic diseases to adult care: current knowledge, practices, and directions. J Pediatr 2006;148:824-7.

24. Friedman DL, Freyer DR, Levitt GA. Models of care for survivors of childhood cancer. Pediatr Blood Cancer 2006;46:159-68.

25. Ginsberg JP, Hobbie WL, Carlson CA, et al. Delivering long-term follow-up care to pediatric cancer survivors: transitional care issues. Pediatr Blood Cancer 2006;46:169-73.

26. Goodman DM, Mendez E, Throop C, et al. Adult survivors of pediatric illness: the impact on pediatric hospitals. Pediatrics 2002;110:583-9.

27. Higgins SS, Tong E. Transitioning adolescents with congenital heart disease into adult health care. Prog Cardiovasc Nurs 2003;18:93-8.

28. Hink H, Schellhase D. Transitioning families to adult cystic fibrosis care. J Spec Pediatr Nurs 2006;11:260-3.

29. Hobbie WL, Ogle S. Transitional care for young adult survivors of childhood cancer. Semin Oncol Nurs 2001;17:268-73.

30. Jones BL. Promoting healthy development among survivors of adolescent cancer. Fam Community Health 2008;31:S61-70.

31. Kelly AM, Kratz B, Bielski M, et al. Implementing transitions for youth with complex chronic conditions using the medical home model. Pediatrics 2002;110:1322-7.

32. Klaas S, Hickey K. Transition to adult care. SCI Nurs 2001;18:158-60.

33. Knauth A, Verstappen A, Reiss J, et al. Transition and transfer from pediatric to adult care of the young adult with complex congenital heart disease. Cardiol Clin 2006; $24: 619-29$, vi.

34. Lewis-Gary MD. Transitioning to adult health care facilities for young adults with a chronic condition. Pediatr Nurs 2001;27:521-4.

35. Lotstein DS, McPherson M, Strickland B, et al. Transition planning for youth with special health care needs: results from the National Survey of Children with Special Health Care Needs. Pediatrics 2005;115:1562-8.

36. MacLean WE Jr, Foley GV, Ruccione K, et al. Transitions in the care of adolescent and young adult survivors of childhood cancer. Cancer 1996;78:1340-4.

37. McPherson M, Weissman G, Strickland BB, et al. Implementing communitybased systems of services for children and youths with special health care needs: how well are we doing? Pediatrics 2004;113:1538-44.

38. Olsen DG, Swigonski NL. Transition to adulthood: the important role of the pediatrician. Pediatrics 2004;113:e159-62. 
39. Østerlund CS, Dosa NP, Arnott Smith C. Mother knows best: medical record management for patients with spina bifida during the transition from pediatric to adult care. AMIA Annu Symp Proc 2005;2005:580-4.

40. Parker HW. Transition and transfer of patients who have cystic fibrosis to adult care. Clin Chest Med 2007;28:423-32.

41. Patterson DL, Lanier C. Adolescent health transitions: focus group study of teens and young adults with special health care needs. Fam Community Health 1999;22:43-58.

42. Rearick E. Enhancing success in transition service coordinators: use of transformational leadership. Prof Case Manag 2007;12:283-7.

43. Reiss J, Gibson R. Health care transition: destinations unknown. Pediatrics 2002:110:1307-14.

44. Reiss JG, Gibson RW, Walker LR. Health care transition: youth, family, and provider perspectives. Pediatrics 2005;115:112-20.

45. Ross HM, Fleck D. Clinical considerations for allied professionals: issues in transition to adult congenital heart disease programs. Heart Rhythm 2007:4:811-3.

46. Sawin KJ, Cox AW, Metzger SG, et al. Transition planning for youth with chronic conditions: an interdisciplinary process. National Academies of Practice Forum: Issues in Interdisciplinary Care (NAPF) 1999;1:183-96.

47. Scal P, Evans T, Blozis S, et al. Trends in transition from pediatric to adult health care services for young adults with chronic conditions. J Adolesc Health 1999;24:259-64.

48. Scal P, Ireland M. Addressing transition to adult health care for adolescents with special health care needs. Pediatrics 2005;115:1607-12.

49. Scal P. Transition for youth with chronic conditions: primary care physicians approaches. Pediatrics 2002;110:1315-21.

50. Tong EM, Kools S. Health care transitions for adolescents with congenital heart disease: patient and family perspectives. Nurs Clin North Am 2004;39:727-40.

51. Turkel S, Pao M. Late consequences of chronic pediatric illness. Psychiatr Clin North Am 2007;30:819-35.

52. White PH. Transition: a future promise for children and adolescents with special health care needs and disabilities. Rheum Dis Clin North Am 2002;28:687-703, viii.

53. Wiener LS, Zobel M, Battles H, et al. Transition from a pediatric HIV intramural clinical research program to adolescent and adult community-based care services: assessing transition readiness. Soc Work Health Care 2007:46:1-19.

54. Zack J, Jacobs CP, Keenan PM, et al. Perspectives of patients with cystic fibrosis on preventive counseling and transition to adult care. Pediatr Pulmonol 2003;36:376-83.

55. Zebrack BJ, Eshelman DA, Hudson MM, et al. Health care for childhood cancer survivors: insights and perspectives from a Delphi panel of young adult survivors of childhood cancer. Cancer 2004;100:843-50.

56. Bowen M. Complex palliative care and transition: a case review. Paediatr Nurs 2007;19:42-5

57. Conway SP. Transition from paediatric to adult-orientated care for adolescents with cystic fibrosis. Disabil Rehabil 1998;20:209-16.

58. Cowland J. NTplus. The role of the cystic fibrosis nurse specialist. Nurs Times 2002:98:62-3.

59. Cowlard J. Cystic fibrosis: transition from paediatric to adult care. Nurs Stand 2003:18:39-41.

60. Edwards J. A model of palliative care for the adolescent with cancer. Int J Palliat Nurs 2001:7:485-8.

61. Foster $\mathbf{L}$, Holmes Y. Transition from paediatric to adult service in epidermolysis bullosa. Br J Nurs 2007:16:244-6.

62. Hudsmith LE, Thorne SA. Transition of care from paediatric to adult services in cardiology. Arch Dis Child 2007:92:927-30.

63. Jordan A, McDonagh JE. Transition: getting it right for young people. Clin Med 2006;6:497-500.

64. Judd A, Doerholt K, Tookey PA, et al. Morbidity, mortality, and response to treatment by children in the United Kingdom and Ireland with perinatally acquired HIV infection during 1996-2006: planning for teenage and adult care. Clin Infect Dis 2007:45:918-24

65. Lowton $\mathbf{K}$, Mathes L, Wyatt $\mathrm{H}$, et al. Evaluation of transition services for young people with cystic fibrosis in Southeast London. J Interprof Care 2005;19:408-9.

66. Lyon A. Transition from paediatric to adult care in cystic fibrosis. Nurse 2 Nurse 2003;3:28-9.

67. Madge $\mathbf{S}$, Bryon M. A model for transition from pediatric to adult care in cystic fibrosis. J Pediatr Nurs 2002;17:283-8.

68. Maunder EZ. The challenge of transitional care for young people with life-limiting illness. Br J Nurs 2004;13:594-6.

69. Maynard L, Rennie T, Shirtliffe J, et al. Seeking and using families' views to shape children's hospice services. Int J Palliat Nurs 2005;11:624-30.

70. McDonagh JE. Growing up ready for emerging adulthood. An evidence base for professionals involved in transitional care for young people with chronic illness and/ or disabilities. 2006.

71. Miles K, Edwards S, Clapson M. Transition from paediatric to adult services: experiences of HIV-positive adolescents. AIDS Care 2004;16:305-14.

72. Miller S. Transition of care in adolescence. Paediatr Nurs 1996:8:14-6.
73. Por J, Golberg B, Lennox V, et al. Transition of care: health care professionals view. J Nurs Manag 2004;12:354-61.

74. Reading R. Lost in transition? Between paediatric and adult services. Child Care Health Dev 2006;32:501-2.

75. Skinner R, Wallace WH, Levitt G. Long-term follow-up of children treated for cancer: why is it necessary, by whom, where and how? Arch Dis Child 2007;92:257-60.

76. Soanes C, Timmons S. Improving transition: a qualitative study examining the attitudes of young people with chronic illness transferring to adult care. J Child Health Care 2004;8:102-12.

77. Stower S. A role in smooth transitions. Paediatr Nurs 1998;10:6.

78. Viner R. Bridging the gaps: transition for young people with cancer. Eur J Cancer 2003;39:2684-7

79. Viner R. Transition from paediatric to adult care. Bridging the gaps or passing the buck? Arch Dis Child 1999;81:271-5.

80. Viner RM. Transition of care from paediatric to adult services: one part of improved health services for adolescents. Arch Dis Child 2008;93:160-3.

81. Whelan J. Where should teenagers with cancer be treated? Eur J Cancer 2003;39:2573-8

82. While A, Forbes A, Ullman R, et al. Good practices that address continuity during transition from child to adult care: synthesis of the evidence. Child Care Health Dev 2004;30:439-52.

83. Beresford B. On the road to nowhere? Young disabled people and transition Child Care Health Dev 2004;30:581-7.

84. Bowes G, Sinnema G. Surís JC, et al. Transition health services for youth with disabilities: a global perspective. J Adolesc Health 1995;17:23-31.

85. Brumfield K Lansbury $\mathrm{G}$. Experiences of adolescents with cystic fibrosis during their transition from paediatric to adult health care: a qualitative study of young Australian adults. Disabil Rehabil 2004;26:223-34.

86. Craig SL, Towns S, Bibby H. Moving on from paediatric to adult health care: an initial evaluation of a transition program for young people with cystic fibrosis. Int J Adolesc Med Health 2007:19:333-43.

87. Kennedy A, Sloman F, Douglass JA, et al. Young people with chronic illness: the approach to transition. Intern Med J 2007:37:555-60.

88. Landau LI. Cystic fibrosis: transition from paediatric to adult physician's care. Thorax 1995:50:1031-2.

89. O'Connell B, Bailey S, Pearce J. Straddling the pathway from paediatrician to mainstream health care: transition issues experienced in disability care. Aust J Rural Health 2003:11:57-63.

90. Sawyer SM, Blair S, Bowes G. Chronic illness in adolescents: transfer or transition to adult services? J Paediatr Child Health 1997:33:88-90.

91. Steinbeck K, Brodie L. Bringing in the voices: a transition forum for young people with chronic illness or disability. Neonatal Paediatr Child Health Nurs 2006;9:22-6.

92. Steinbeck KS, Brodie L, Towns SJ. Transition care for young people with chronic illness. Int J Adolesc Med Health 2007:19:295-303.

93. Yeo M, Sawyer SM. Strategies to promote better outcomes in young people with chronic illnesses. Ann Acad Med Singap 2003;32:36-42.

94. Blum RW. Introduction. Improving transition for adolescents with special health care needs from pediatric to adult-centered health care. [Erratum appears in Pediatrics 2003;111:449] Pediatrics 2002;110:1301-3.

95. Dore A, de Guise P, Mercier LA. Transition of care to adult congenital heart centres: what do patients know about their heart condition? Can J Cardio/ 2002:18:141-6.

96. Gall C, Kingsnorth S, Healy H. Growing up ready: a shared management approach. Phys Occup Ther Pediatr 2006:26:47-62.

97. Morin J, Lynch L. Transition in the 21st century: a tool that promotes seamless transfer of care. Can J Cardiovasc Nurs 2006:16:55.

98. Reid GJ, Irvine MJ, McCrindle BW, et al. Prevalence and correlates of successful transfer from pediatric to adult health care among a cohort of young adults with complex congenital heart defects. Pediatrics 2004;113:e197-205

99. Stewart D, Stavness C, King G, et al. A critical appraisal of literature reviews about the transition to adulthood for youth with disabilities. Phys Occup Ther Pediatr 2006;26:5-24.

100. Taylor L, Tsang A, Drabble A. Transition of transplant patients with cystic fibrosis to adult care: today's challenges. Prog Transplant 2006;16:329-34; quiz 335.

101. Young N, McCormick A, Mills W, et al. The transition study: a look at youth and adults with cerebral palsy, spina bifida and acquired brain injury. Phys Occup Ther Pediatr 2006;26:25-45

102. Berg SK, Hertz PG. Outpatient nursing clinic for congenital heart disease patients: Copenhagen Transition Program. J Cardiovasc Nurs 2007;22:488-92.

103. Michaud PA, Suris JC, Viner R. The adolescent with a chronic condition. Part II: healthcare provision. Arch Dis Child 2004:89:943-9.

104. Steinkamp G, Ullrich G, Müller C, et al. Transition of adult patients with cystic fibrosis from paediatric to adult care - the patients' perspective before and after start-up of an adult clinic. Eur J Med Res 2001;6:85-92.

105. Westwood A Henley L, Willcox P. Transition from paediatric to adult care for persons with cystic fibrosis: patient and parent perspectives. J Paediatr Child Health 1999:35:442-5. 